Literatura y Lingüística $\mathrm{N}^{\circ} 26$

ISSN 0716-5811 / pp. 115-133

\title{
Migración, retorno y lenguaje en la narrativa latinoamericana de hoy: El espíritu de mis padres sigue subiendo en la lluvia de Patricio Pron $^{*}$
}

\author{
Pamela Tala**
}

\section{Resumen}

Este artículo examina de qué manera en su más reciente novela, El espíritu de mis padres sigue subiendo en la lluvia, el joven escritor argentino Patricio Pron, expone, creativamente, al menos dos procesos fundamentales: en primer lugar, el texto enfrenta al lector al complejo proceso contemporáneo de migración/retorno en la narrativa latinoamericana de hoy y a algunas de las construcciones de sentido que este proceso forja. Por otro lado (y al mismo tiempo), la máquina narrativa establecida por Pron, logra relacionar/articular el tema migración/retorno con las inevitables operaciones que acontecen al interior del lenguaje literario, el cual, exigido hasta los límites de su expresión, busca diferentes formas de manifestar la experiencia vital del narrador, de su familia y de su país.

Palabras clave: narrativa latinoamericana, migración, retorno, lenguaje.

\section{Migration, return and lenguaje in current Latin American narrative: El espíritu de mis padres sigue subiendo en la lluvia by Patricio Pron}

\begin{abstract}
This article examines how, in his last novel, El espíritu de mis padres sigue subiendo en la lluvia, the young Argentinean writer, Patricio Pron, creatively presents, at least two processes: first, he shows the reader the complex process of migration/return and some related constructions of meaning. On the other hand (and at the same time), the narrative machine set up by Pron relates/ articulates the migration/return theme to the unavoidable operations ocurring in literary language, which demanded until its limits of its expression, seeks different ways to express the vital experience of the narrator, his family and his country.
\end{abstract}

Keywords: Latin American narrative, migration, return, language.

Recibido: 11-04-2012Ａceptado: 09-07-2012

* Este artículo ha sido escrito en el marco del Proyecto de Postdoctorado N³120190, financiado por Fondecyt y patrocinado por la Pontificia Universidad Católica de Chile.

* Dra. en Literatura Hispanoamericana. Actualmente: Postdoctorado en Literatura (Fondecyt/ Pontificia Universidad Católica).Chile. pamela.tala@coloradocollege.edu 
Migración, retorno y lenguaje en la narrativa latinoamericana de hoy: El espíritu de mis padres sigue subiendo en la lluvia de Patricio Pron / Pamela Tala

La novela del retorno solo puede ser una novela inacabada.

(Patricio Pron)

... para mí la escritura surge precisamente del desplazamiento y de la pérdida: pérdida de un punto de partida, de un lugar de origen, en suma, de

una casa irrecuperable.

(Sylvia Molloy 2005)

La novela de Patricio Pron El espíritu de mis padres sigue subiendo en la lluvia (Madrid: 2011) habla acerca del retorno. Recientemente, la crítica argentina Silvia Molloy, en una de sus visitas a Buenos Aires, ha señalado: "En palabras de Leonardo Sciascia: cuando uno ha cometido el error de irse, no debe cometer el error de volver." (Molloy 2011: 47). De alguna manera, este artículo interroga esa aseveración de Molloy en la novela de Patricio Pron: ¿cuál es el retorno articulado en la narrativa latinoamericana de hoy?, ¿en qué posición está el sujeto del retorno?, ¿qué operaciones acontecen en el lenguaje literario que lo nombra?, ¿cuáles en su propio lenguaje?, ¿cuáles son las posibilidades del retorno, cuáles las clausuras? Son algunas de las preguntas de este ensayo acerca de la última novela de este escritor.

Patricio Pron nació en Rosario, Argentina, en 1975². Hijo de padres periodistas, Pron es licenciado en Comunicación Social en la Universidad Nacional de Rosario. En 1992 comenzó a ejercer la actividad periodística, desempeñándose en varios medios. En el año 2000 deja Argentina y comienza a recorrer Europa. Obtuvo el doctorado en Filología Románica en la Universidad de "Georg-August", Göttingen,

1 Patricio Pron en entrevista, Madrid, junio, 2011. Agradezco al escritor Patricio Pron esa entrevista donde no solo me iluminó acerca de aspectos de su obra en general sino, también, en no menor medida, acerca del estado de la literatura latinoamericana de hoy.

2 Su trabajo ha sido premiado, entre otros, con el premio Juan Rulfo de Relato 2004 y el Jaén de Novela 2008, y antologado en Argentina, España, Alemania, Estados Unidos, Colombia y Cuba. Sus relatos han aparecido en publicaciones como The Paris Review y Zoetrope (Estados Unidos), die horen (Alemania), Etiqueta Negra (Perú), Esquire (México), Eñe y Granta (España). Su trabajo como crítico es publicado regularmente en medios como ADN Cultura de La Nación (Buenos Aires), Quimera, Letras Libres y Revista de Libros, entre otros. Pron es autor de los volúmenes de relatos Hombres infames (1999) y El vuelo magnifico de la noche (2001) y de las novelas Formas de morir (1998), Nadadores muertos (2001), Una puta mierda (2007) y El comienzo de la primavera (Literatura Mondadori, 2008), distinguida por la Fundación José Manuel Lara como una de las cinco mejores obras publicadas en España ese año. Es doctor summa cum laude en filología románica por la Georg-August-Universität de Göttingen (Alemania). Ha publicado en 2010 el libro de relatos El mundo sin las personas que lo afean y lo arruinan (Literatura Mondadori). Su libro más reciente es El espíritu de mis padres sigue subiendo en la lluvia (Literatura Mondadori, 2011).

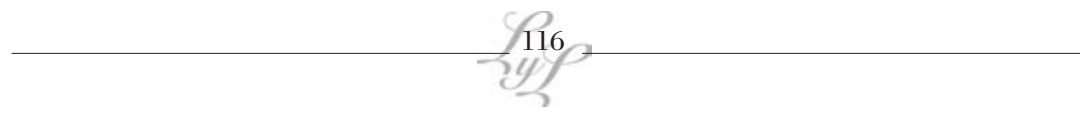


Alemania, con una tesis acerca de los procedimientos narrativos en la obra de Copi y actualmente se encuentra viviendo en Madrid. Ha publicado varias novelas. Por otro lado, su trabajo narrativo como cuentista está presente de manera notoria en diversas antologías en las que se lo sitúa junto a un grupo de escritores con los cuales comparte, al menos, algunos rasgos circunstanciales: algunos de ellos nacieron después de 1960 y muchos después de 1970. Nacidos en América Latina y formados en el contexto socio-económico-cultural del capitalismo tardío y del neoliberalismo implantado de manera brutal en estos países. Son escritores que, por otro lado, ya no son contemporáneos del boom de la literatura latinoamericana (por lo tanto no hay en ellos ninguna necesidad de "matar al padre"; más bien se han reconciliado con los grandes abuelos ${ }^{3}$ y también han crecido en un contexto en el cual los grandes relatos épicos del siglo XX se encuentran ya casi completamente desmantelados. Desde esa posición, desde esas posiciones, más escépticos y cínicos que desencantados (porque muchos de ellos nunca vivieron el encanto de lo colectivo), se sitúan en un lugar de alguna manera provocativo y productivo para, por un lado, develar, narrando el presente, algunas oscuridades que el discurso triunfalista neoliberal prefiere mantener acalladas y, por otro, para seguir interrogando el sistema literario latinoamericano ${ }^{4}$ acerca de nociones como identidad, subjetividades, lo nacional e, incluso, la patria; nociones que ya para algunos parecían desterradas.

3 "A pesar de los malentendidos periodísticos (...), no conozco el caso de un solo escritor hispanoamericano de mi edad que haya buscado asesinar (ni siquiera de manera simbólica) a Fuentes, García Márquez o Vargas Llosa. Experiencias como la antología McOndo o el Manifiesto del Crack revelaban, más bien, el intento de escapar de la marca 'narrativa hispanoamericana'; ello no implicaba, en ningún caso, abjurar del boom -el cual, por el contrario, encarnaba la posibilidad de engarzarse con una de las tradiciones más ricas de la literatura hispanoamericana-, sino de la manipulación académica, comercial y crítica que le siguió; es decir, de denunciar la puesta en funcionamiento de una especie de maquila literaria para la exportación del exotismo regional. La metáfora de la producción en serie resulta de lo más adecuada: se luchaba contra la idea de convertir a los escritores hispanoamericanos en una especie de sucursales locales de Hispanoamérica, Inc., una empresa o mejor un holding interesado en distribuir en todo el mundo libros auténticamente hispanoamericanos con la misma desenvoltura con que se podía vender una franquicia de Taco Bell y decir que se trataba de comida auténticamente mexicana" (Volpi en Montoya y Esteban eds. 2008:104)

4 En palabras de Ángel Rama: "Una literatura es entendida, aquí, no como una serie de obras de valor, sino como un sistema coherente con su repertorio de temas, formas, medios expresivos, vocabularios, inflexiones lingüísticas, con la existencia real de un público consumidor vinculado a los creadores, con un conjunto de escritores que atienden las necesidades de ese público y que por lo tanto manejan los grandes problemas literarios y socioculturales. Los tres sectores componen una estructura de desarrollo histórico que por lo mismo sobrevive a las distintas etapas de integración de sus partes, imponiendo la permanencia del pasado -de un pasado vivo, que pesa y actúa- sobre las diversas inflexiones de un sucesivo presente". (Rama, 1985:11-12). 
Migración, retorno y lenguaje en la narrativa latinoamericana de hoy: El espíritu de mis padres sigue subiendo en la lluvia de Patricio Pron / Pamela Tala

Muchos de estos escritores han decidido vivir fuera de sus países de origen y, de alguna manera, este fenómeno ha des-orientado -especialmente a cierto sector de la crítica especializada- reformulando el concepto de identidad y de escritor latinoamericano hacia nuevos moldes que ellos nombran desde su propia experiencia: la expresión "Mi poncho es un kimono flamenco" condensa el itinerario personal del escritor peruano Fernando Iwasaki; Juan Gabriel Vásquez, colombiano, se siente como un "inquilino" en España después de haber vivido en Francia y en Bélgica; Gonzalo Garcés se define como "un argentino portátil" y Andrés Neuman, por su lado, habla de "una dichosa extranjería" desde su actual residencia en Granada, España. Están alcanzando su madurez literaria en el extranjero. Sin embargo, la mayoría de ellos, sigue narrando desde su condición de latinoamericanos; incluso en casos tan extremos e interesantes como el escritor nacido en Perú, Daniel Alarcón, quien escribe acerca de su país de origen desde Estados Unidos, en inglés. Al parecer, la definición de escritor latinoamericano se mantiene tradicional y vitalmente re-formulada. El crítico Daniel Noemí reconoce algunos rasgos comunes en esta narrativa:

De hecho, creo que con todas sus múltiples variantes, estilos y estéticas, estos textos -[...], la gran mayoría de la producción narrativa latinoamericana contemporánea-, que sí circulan en el mercado, que no existen fuera de él, construyen una constelación que posee una fuerza crítica radical en su novedad y en su modo de ser. No son textos revolucionarios, pero sí son textos que por su misma participación en el mercado son capaces de mostrar y de mostrarnos a nosotros, desocupados lectores, un funcionamiento social y político contemporáneo. Indican y apuntan a la transformación de un mundo, de nuestro mundo y su sociedad y desde ese trabajo, donde la violencia y el sexo, la historia y las drogas, el fracaso y el exceso se amalgaman y comparten tinta, permiten pensar alternativas para lo político y la política. En breve, estos textos pueden ser pensados como pertenecientes a una nueva forma de realismo (...). Un realismo que se ha hecho cargo del legado realista decimonónico, social, mágico y sucio, y que ha hecho suyas, también, las experiencias de las vanguardias, tanto las históricas como las posteriores. (Noemi en Montoya y Esteban eds. 2008:94)

Por otro lado, los datos biográficos mencionados anteriormente no son solo anecdóticos, porque estas experiencias de migración (y/o retorno) son las narradas en la obra de estos autores, quienes,

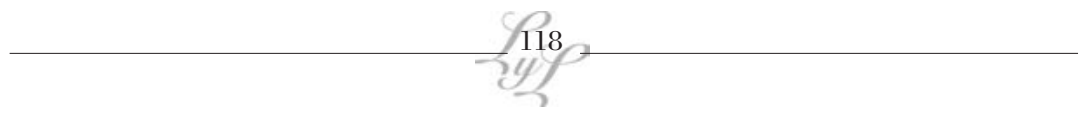


también están desafiando los límites del género narrativo, escribiendo de una manera que la crítica argentina Josefina Ludmer ha llamado la "ficción/no ficción" (Ludmer 2010), lo que complejiza la interpretación: ¿cómo tenemos, cómo tiene que leer la crítica literaria estas narraciones, tremendamente referenciales, que difuminan el límite de la ficción? Tal vez una posible respuesta a esta interrogante esté dada en el uso del término autoficción. Serge Doubrovsky, novelista francés, es considerado el inventor del término al utilizarlo a modo de explicación de su obra aparentemente ficcional titulada Fils (1977). Philippe Lejeune, por su parte, se hizo eco más tarde de este neologismo. El éxito del término, sin embargo, pudo reflejarse luego en la cita que hace de él el libro de Gérard Genette titulado Palimpsestes (1982). El término venía a llenar un formidable vacío, llamando la atención sobre el ingrediente ficcional de algunas obras que parecían cumplir el pacto autobiográfico.

Considerando el marco anterior, este artículo examina de qué manera, en esta, su más reciente novela, El espiritu de mis padres sigue subiendo en la lluvia, la narración de Pron le permite investigar creativamente por lo menos dos procesos: primero, expone al lector al complejo proceso migración-retorno a algunas de las construcciones de sentido que la migración y el retorno proveen. Por otro lado (y al mismo tiempo), la maquinaria narrativa que monta Pron logra relacionar/articular el tema migración/retorno con las operaciones que inevitablemente acontecen en el lenguaje literario, exigido hasta los límites de su expresión, en ese acontecer vital del narrador.

\section{Las posibilidades del retorno: "dejarlo todo atrás, de alguna forma"}

La novela de Pron se interroga, haciendo uso de diversos recursos, acerca del sentido del viaje y de la narración de este y del desplazamiento. También acerca del modo en que se vehicula o se interroga la posibilidad del retorno.

En El espíritu de mis padres sigue subiendo en la lluvia, el narrador es un escritor argentino de alrededor de 30 años que relata el regreso a su país de origen (del que había salido cuando tenía 18 años) desde Alemania, después de saber que su padre se encuentra hospitalizado, repentina y gravemente enfermo. Ese retorno lo obligará, finalmente, a reconocer(se) al involucrarse, primero como espectador -casi por azar-en la historia 
Migración, retorno y lenguaje en la narrativa latinoamericana de hoy: El espíritu de mis padres sigue subiendo en la lluvia de Patricio Pron / Pamela Tala

familiar, que no es otra, metonímicamente, que la dramática historia reciente de Argentina.

No se cuenta con muchos datos acerca de la circunstancia vital del narrador durante su estadía en Alemania. O, más bien, se informa al lector de los síntomas, pero no de las causas del estado que él describe como: desposeído, desprotegido, aturdido por las muchas pastillas que ingiere a diario, durmiendo en sofás de conocidos, en la precariedad, a la intemperie emocional y física:

Unos meses antes de que enfermara (mi padre), yo había dejado la habitación que rentaba en aquella ciudad alemana y había comenzado a dormir en los sofás de las personas que conocía. No lo hacía porque no tuviera dinero sino por la irresponsabilidad que, suponía, traía consigo no tener casa ni obligaciones, dejarlo todo atrás de alguna forma. (14)

o

[... ] sobre la hierba al que solía ir a matar las horas del día antes de salir a buscar la hospitalidad y la compañía del dueño o la dueña de algún sofá. Yo, simplemente, estaba de paso. (14)

Este es el punto de habla narrativo: el desamparo. La escritura nace de la intemperie. El héroe no describe el inicio de su peripecia como un origen prístino hacia un viaje iniciático ni menos hacia un retorno a casa tranquilizador, una especie de salvación. Ni siquiera confiado en encontrar una verdad parcial. Por el contrario, se trata de un héroe que comienza el relato ya dañado, que comienza el regreso ya destruido, aturdido por las píldoras, extranjero de sí mismo, extraviado. Es más, su retorno no es deseado o programado; por el contrario, es planteado como un regreso a un país -el suyo- del cual "escapó" y al que se ve obligado a regresar (desde esta suerte de anomia ${ }^{5}$ en la que se encontraba viviendo) por la emergencia en la salud del padre.

Producto de esa misma situación de precariedad e intemperie, el tono predominante del narrador es el de la duda: exhibe -y/o advierteconstantemente al lector a lo largo del texto acerca de la escasa fiabilidad de su voz, una voz desmantelada por sí mismo. Se trata de un sujeto intentando desproveerse de todo tipo de autoridad, que insiste en instalar la duda, la desconfianza y el desconcierto:

5 En las dos acepciones que da el Diccionario de la Real Academia:

. f. Psicol. y Sociol. Conjunto de situaciones que derivan de la carencia de normas sociales o de su degradación.

.f. Med. Trastorno del lenguaje que impide llamar a las cosas por su nombre.

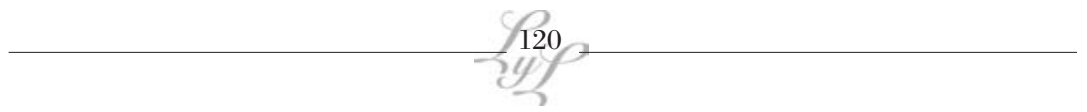


Entre marzo o abril de 2000 y agosto de 2008, ocho años en los que viajé y escribí artículos y viví en Alemania, el consumo de ciertas drogas hizo que perdiera casi por completo la memoria, de manera que el recuerdo de esos años -por lo menos el recuerdo de unos noventa y cinco meses de esos años- es más bien impreciso y esquemático (11)

Este narrador, en apariencia, no aspira a crear ninguna verosimilitud. O, mejor, podría decirse, la única verosimilitud que se esmera en fabricar es la de la imposibilidad del relato, del recuerdo, de la verdad con mayúscula, del, en definitiva, decir: "Aunque quizá esto no haya sucedido realmente (lo del aeropuerto) y todo haya sido un error o un engaño inducido por las pastillas que aquel médico me daba (25)". Una de las consecuencias más relevantes, literariamente, que esto trae consigo, es el hecho narrativo de la constante destrucción (o al menos desestabilización) del contrato de ficción:

[...] yo pensaba que había venido de los oscuros bosques alemanes a la llanura horizontal argentina para ver morir a mi padre y para despedirme de él y prometerle -aunque yo no lo creyera en absoluto- que él y yo íbamos a tener otra oportunidad, en algún otro sitio, para que cada uno de nosotros averiguara quién era el otro y, quizá, por primera vez desde que él se había convertido en padre y yo en hijo, por fin entendiéramos algo; pero esto, siendo verdadero, no era en absoluto verosímil”. (27)

Resultaba "verdadero", sin embargo, "no verosímil". Al pacto con los lectores, al pacto de reconocimiento mutuo del narrador con su propio padre, al pacto de amor entre dos personas, le basta con la verosimilitud; de ahí el tono de amargura que reina en gran parte del texto de Pron: ya no era posible creer (ya no es posible creer). Lo reafirma el narrador/ protagonista en el siguiente fragmento:

Como quiera que sea, aquel encuentro, que ocurrió realmente y que, por tanto, fue verdadero, puede leerse aquí sencillamente como una invención, como algo falso [...] y casi todo lo que sucedió después, lo que yo vengo a contar, fue verdadero, pero no necesariamente verosímil. (25)

En las citas anteriores resuenan, como en un eco, las siguientes líneas de Emma Zunz de Jorge Luis Borges: "La historia era increíble, en efecto, pero se impuso a todos, porque sustancialmente era cierta. Verdadero era el tono de Emma Zunz, verdadero el pudor, verdadero el odio. Verdadero también era el ultraje que había padecido; solo eran falsas 
Migración, retorno y lenguaje en la narrativa latinoamericana de hoy: El espíritu de mis padres sigue subiendo en la lluvia de Patricio Pron / Pamela Tala

las circunstancias, la hora y uno o dos nombres propios" (O.C., I, 568). La cita borgeana resuena a lo largo de todo el discurso narrativo de la novela de Pron y establece uno de los ejes sobre los que se estructura su relato: la desestabilización de la oposición entre lo verdadero o lo falso, entre lo verdadero o lo verosímil, entre lo increíble y lo verosímil y la importancia asignada a estas distinciones: "Esto significa que la dosis de verdad que contienen las frases que Emma pronuncia en el teléfono la noche del crimen debería medirse, como teoriza Wittgenstein en el Tractatus y como coincide el propio Borges en sus "refutaciones del tiempo", menos por su relación con un referente empírico que por su éxito o fracaso al producir una fórmula que al destinatario le parezca apropiada a la naturaleza profunda del caso" (Rojo, 2009: 28). Eso es lo que, a su modo y con sus recursos, Patricio Pron está haciendo con sus lectores. Este narrador solo puede ser verosímil en la misma falta de verosimilitud o en la insistencia de ella. Insiste en proclamar que no es fiable, que no recuerda, se contradice, se desdice, constantemente.

Más adelante veremos cómo el narrador y el lenguaje del narrador van sufriendo cambios a medida que el sujeto, ya en Argentina, se va apropiando de la historia política de su padre, del pasado militante y comprometido de su padre y de los amigos de este (y se va produciendo una suerte de anagnórisis en el protagonista). Pero hasta antes que eso ocurra, la introspección y distanciamiento con el "mundo de afuera" del narrador encuentra diversas maneras de expresarse o, más bien, de ilustrarse. Una faceta de esta introspección, de este distanciamiento, es el misterio y la amenaza de la familiaridad que se vuelve ajena. El protagonista deviene un extraño en un ambiente familiar o, visto desde otro punto de vista, el familiar en un ambiente que se le ha vuelto extraño: "Mi madre entró en la cocina y me encontró observando los productos en la nevera. Como en esos sueños en los que todo es sospechosamente familiar y al mismo tiempo escandalosamente extraño (...)" (29). En este sentido, la extrañeza venida por lo ominoso (freudiano) ronda gran parte del discurso del narrador de esta novela, hasta que se va adentrando - especularmente- casi a ciegas en la investigación que su propio padre estaba llevando a cabo y en el conocimiento del pasado político comprometido de sus padres y de los amigos de estos. Pero hasta ese encuentro, hasta que se produce el verdadero retorno o la verdadera posibilidad de retorno, la familia y la vida familiar aparecen en el discurso del narrador como un accidente inadvertido:

Algo nos había sucedido a mis padres y a mí y a mis hermanos y había hecho que yo jamás supiera qué era una casa y qué era

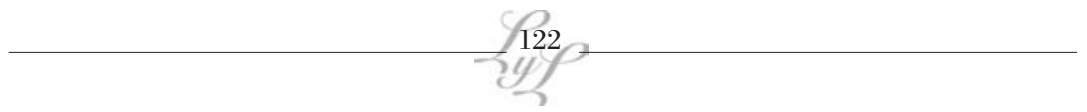


una familia [...] Yo había intentado muchas veces en el pasado comprender qué había sido eso, pero por entonces y allí, en Alemania, ya había dejado de hacerlo, como quien acepta las mutilaciones que le ha infligido un accidente automovilístico del que nada recuerda. Alguna vez mis padres y yo habíamos tenido ese accidente: algo se había cruzado en nuestro camino y nuestro coche había dado un par de vueltas y se había salido de la carretera, y nosotros estábamos ahora deambulando por los campos con la mente en blanco, y lo único que nos unía era ese antecedente en común. A nuestras espaldas había un coche volcado en la cuneta de un camino rural y manchas de sangre en los asientos y en los pastos, pero ninguno de nosotros quería darse la vuelta y mirar a sus espaldas. (18 y 19).

El párrafo anterior funciona como uno de los varios espejos que estructura la narración. La imagen del coche volcado producto de un accidente que nadie advirtió y que, más aun, nadie supo prever o detener y del cual solo se sufren -aún y de manera permanente en el tiempo- las consecuencias mudas y dolientes de esa herida, no hace sino recordar la manera en que las dictaduras militares en el Cono Sur provocaron -a traición, sin racionalidad comunicativa alguna- el horror. Horror frente al cual se enmudece o se balbucea, hasta encontrar una nueva manera de nombrar. Tal como ocurre a lo largo de la novela de Pron. Así, en el párrafo anterior, al igual que en otros varios fragmentos de la novela, vemos, especularmente, una alegoría de la pequeña comunidad familiar y una alegoría del drama nacional.

\section{La migración del lenguaje}

La experiencia migratoria o del desplazamiento, se instala en esta novela de Pron, no solo temáticamente, sino -y con gran relevancia- también en el nivel de la lengua literaria (como si, de alguna manera, no solamente sea el personaje-narrador, el migrante que regresa del extranjero, sino también el propio lenguaje -o la posibilidad de decir). Y es uno de los rasgos que distingue esta novela de gran parte de la narrativa actual: su nivel de conciencia acerca de la lengua como el material con el que está trabajando y que organiza de manera tal que le permita expresar los diferentes estados por los que atraviesa el narrador. Este volverse el lenguaje sobre sí mismo, estableciendo constantemente juegos de espejos metaficcionales que al mismo tiempo interrogan posibilidades 
Migración, retorno y lenguaje en la narrativa latinoamericana de hoy: El espíritu de mis padres sigue subiendo en la lluvia de Patricio Pron / Pamela Tala

y límites de manera incisiva, distingue, sin duda, la escritura de ficción de Patricio Pron de gran parte de sus contemporáneos.

Enfrentado el retorno, en Argentina, teniendo en sus manos el material que había reunido su padre para la investigación que estaba llevando a cabo, durmiendo en su habitación de adolescente, enfermo y mirando televisión junto a su hermano, cocinando en silencio con su madre o visitando a su padre en el hospital, el narrador de El espíritu de mis padres sigue subiendo en la lluvia acorrala el lenguaje que hasta ahora vehiculizaba su experiencia y busca, explora, la manera de expresar el proceso que vive. Sin embargo, a lo largo de las páginas, nos vamos dando cuenta de la complejidad de la voz narrativa y de lo insuficiente que se le vuelve. No es un sujeto que transite desde la ignorancia y la indiferencia completa de la historia de su familia y de su país hacia una toma de conciencia absoluta y comprometida (lo cual simplificaría -hasta hacerlo pueril- este proceso de retorno). El narrador vuelve a Argentina empujado por la hospitalización de urgencia que sufre su padre. Una vez allí, escarbando entre sus papeles (el padre es periodista, a él "sí le interesa la verdad", nos dirá el narrador), el protagonista descubre que su padre había estado investigando la desaparición de un conocido del pueblo donde él nació y creció; persona que después aparece muerta. En los papeles también descubre una foto en la que aparece su padre en el funeral. Investigando los papeles de su padre y hablando escuetamente con su madre, el protagonista descubre que el hombre asesinado era hermano de Alicia, amiga de la juventud de su padre, asesinada (y hecha desaparecer) por los aparatos represores de la dictadura argentina. A esa serie de revelaciones, se suma el conocimiento y la comprensión más profunda de los alcances del compromiso de sus propios padres en el pasado y de la "derrota" (desarticulados política y socialmente, torturados, desaparecidos y/o asesinados por las fuerzas de la dictadura) que ellos y sus compañeros habían sufrido.

En la medida en que estos descubrimientos acontecen (ante los ojos del narrador/escritor devenido lector asombrado y perplejo), paulatinamente se constata de qué manera el narrador encierra el lenguaje dentro de estrechos límites, evidenciando la imposibilidad de decir el horror o la aparente inutilidad del lenguaje frente al horror.

Se podría afirmar que la experiencia de la migración y, mucho más, en este caso, la del retorno, unidas ambas a la develación del horror, deja al sujeto-narrador, en primera instancia, en una situación de agramaticalidad absoluta: desde sus primeros pasos en el aeropuerto hasta la situación (que debería ser cotidiana) de mirar la televisión con su hermano, el

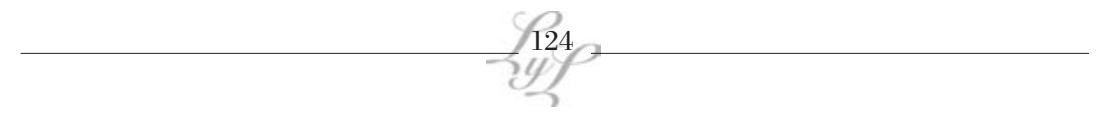


narrador/personaje: "no entiende nada", "[...] a los automovilistas que seguían su camino, aullando al pasar palabras que yo no comprendía". Está desarticulado. Esa perplejidad produce agujeros en el relato (que el texto grafica, por ejemplo, en la ausencia de algunos números en las secciones de la novela). A partir de su conocimiento de lo ocurrido con el "desaparecido" que investigaba su padre, el narrador transita desde su introspección ahora asombrada y muda, perpleja, al relato de una serie de hechos "externos" de difícil conexión. Esa perplejidad se expresará en el lenguaje literario a través de diversas modalidades; diversas modalidades del lenguaje de un sujeto (el narrador) en búsqueda de expresión. Se percibe en este sujeto la urgencia de enunciar, aun cuando deba transitar de la mudez, al balbuceo, a la enumeración y entonces a la enunciación subjetiva, amorosa y en la que se reconoce, y reconoce su historia y la de su familia al final. De esta manera, nos encontramos con diversas modalidades del lenguaje que expresa, al mismo tiempo que los límites de este mismo (el significante constantemente desplazado, huidizo), la necesidad de seguir nombrando, recordando ${ }^{6}$.

Una de las modalidades es presentar la realidad con la distancia del listado. Por ejemplo, la lista que resume la biografía del narrador:

Un tiempo antes de que todo esto sucediera había intentado hacer una lista de las cosas que recordaba de mí mismo y de mis padres [...]. Decía: Tuve una hepatitis grave cuando tenía unos cinco o seis años; a continuación, o antes, tuve escarlatina, varicela y rubéola [...]. Nací con los pies planos y éstos tuvieron que ser corregidos con unos zapatos enormes que me avergonzaban horriblemente [...]. Fui vegetariano durante un par de años y ahora, sin serlo, casi no como carne. Aprendí a leer a los cinco años por mi cuenta [...]. Mi madre dice que no lloré durante los primeros días de mi vida, mi cabeza era tan grande que, si me dejaban sentado, yo comenzaba a bascular y caía de cabeza hacia un costado u otro. [...] Perdí la virginidad a los 15 años. [...] Mi abuelo paterno era pintor, mi abuelo materno era anarquista y el segundo peronista, creo [...]. (46 y 47)

6 Conviene destacar la etimología del verbo recordar: "Recordar: 'tener recuerdo de algo', 1220-50. Del lat. RECORDARI id. (deriv. de COR 'corazón'). De este verbo derivó además el castellano su acordarse 'tener memoria de algo', 1240, ajeno a las demás lenguas romances. Para recordar 'despertar' V. acordar II.

DERIV. Recordación, 1438. Recordatorio. Recuerdo, h. 1250. Trascordarse, h. 1280. (Corominas 2008: 470) 
Migración, retorno y lenguaje en la narrativa latinoamericana de hoy: El espíritu de mis padres sigue subiendo en la lluvia de Patricio Pron / Pamela Tala

Y así continúa la narración durante un par de páginas más, acerca del primer disco, las primeras canciones, su acercamiento y posterior alejamiento del catolicismo, sus comidas favoritas, los idiomas que habla, para concluir: "No me importaría morir, pero temo a la muerte de quienes aprecio, y sobre todo a la muerte de mis padres" (49). Resulta muy sorprendente cómo el aparente distanciamiento a través del uso del enumerado y distanciado listado resume la vida de un hombre joven, enfrentado a la tal vez más difícil situación de su vida (la grave enfermedad de su padre), para finalmente, claudicar, renunciar a la distancia y muy sobriamente, diríamos, incluso, con elegancia, retoma el tono afectivo del género autobiográfico y solamente dice: "Temo que mi padre muera". Esa variedad y esa inteligencia y asertividad en el uso de la lengua (no) literaria, es tal vez una de las características más notorias de la prosa de Pron.

Otro ejemplo de lo mismo es lo que acontece cuando contempla a su madre cocinar y entonces decide ayudarla. Pero en este momento, cuando han regresado del hospital, ocurre una suerte de cambio de registro, porque, ahora, la fabricación de la lista es el intento desesperado por fijar ese momento cálido:

Mi madre comenzó a preparar una comida y yo [...] me puse a ayudarla. Mientras pelaba las cebollas pensé que aquella receta, en su gloriosa simplicidad de otras épocas, iba a perderse pronto en una época de confusión y estupidez, y me dije que debía conservar al menos - puesto que perpetuar ese momento de felicidad compartida, quizá uno de los últimos con mi madre antes de que yo regresara a Alemania, era imposible-que tenía que perpetuar esa receta antes de que fuera tarde. Cogí un bolígrafo y comencé a tomar nota para no olvidarme de aquel momento pero todo lo que pude hacer fue apuntar la receta; una simple receta breve y sin embargo relevante para mí allí y entonces por ser un remanente de un tiempo de procedimientos, de un tiempo de pasos precisos y puntuados, tan diferente de esos días de un dolor que nos embotaba a todos. (40)

Y a continuación sigue la sencilla descripción-lenguaje procedimental: "tiempo de procedimientos"- de la receta de un simple plato casero. Lo que llama la atención en este fragmento (a diferencia del listado de libros, por ejemplo) es la ya explícita necesidad del narrador de vincularse afectivamente, sin distancia, con ese momento perdurable, intentando retenerlo. Incapacitado aun de describir sus emociones, sin

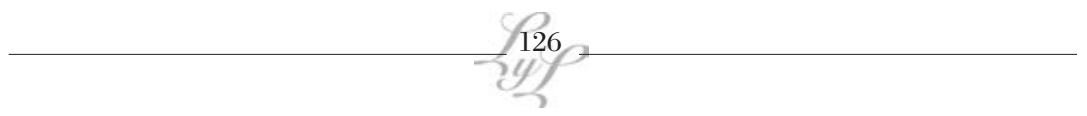


embargo, puede escribir el listado de ingredientes y el procedimiento en la cocina y serán su recordatorio emocional, frente a lo que en ese instante de dolor el lenguaje no le dio las herramientas para decir. La receta -el lenguaje - no es otra cosa que la prolongación de su hogar, una de sus casas subjetivas.

Otra modalidad que adopta este lenguaje (en proceso) del distanciamiento, es la del inventario, el lenguaje inventarial. Un ejemplo claro de esto es una situación cotidiana, en la casa de los padres del narrador (espacio seguro, familiar), donde, sin embargo, el narrador da a conocer de la siguiente manera la biblioteca de sus padres:

Títulos presentes en la biblioteca de mis padres [...]

(Sigue una lista de 34 títulos)

Autores presentes en la biblioteca de mis padres [...]

(Sigue una lista de 21 títulos)

Autores ausentes en la biblioteca de mis padres: Bullrich, Silvina; Guido, Beatriz; Martínez Estrada, Ezequiel; Ocampo, Victoria; Sábato, Ernesto. Colores predominantes en las portadas de los libros de la biblioteca de mis padres: celeste, blanco y rojo. Editoriales más representadas en su biblioteca: Plus, Ultra, A. Peña Lillo, Freeland y Eudeba. Palabras que más aparecen presumiblemente en los libros de la biblioteca de mis padres: táctica, estrategia, lucha, Argentina, Perón, revolución. Estado general de los libros de la biblioteca de mis padres: malo y, en algunos casos, fatal, miserable o pésimo. (35 y 36)

Una modalidad más que adopta el lenguaje literario es el del expediente, el de comunicar la realidad de un hecho, a través de muy pocos comentarios y, más bien, transcribiendo (como queriendo decir no estoy haciendo literatura, es solo una mala transcripción) muy literalmente, las hojas legales. De esta manera, el narrador intenta, infructuosamente, como se ve al final de la novela, hacer explícita una distancia con un hecho que (cree) no le pertenece; una suerte de intento de despersonalización a través de una evidencia también corrupta: fotografías borrosas, reportes policiales mal escritos (el texto acude constantemente a palabras como "sic", "ilegible", "tachado"). Imposibilidad de la Historia.

Del mismo modo, más de una vez, encontramos la voz del narrador exponiendo un listado de síntomas o de medicinas o de efectos laterales, en un lenguaje que llamaremos prescriptivo, en un intento de solapar (o de 
Migración, retorno y lenguaje en la narrativa latinoamericana de hoy: El espíritu de mis padres sigue subiendo en la lluvia de Patricio Pron / Pamela Tala

nombrar sin decir) el estado emocional con el que ha estado batallando, a través de una enumeración caótica:

Leí que aquellas pastillas tenían un efecto sedativo, antidepresivo y ansiolítico [...]; leí que produce dependencia física y psicológica y que induce amnesia además de la disminución o la falta completa de la capacidad para recordar los eventos que tengan lugar durante los periodos de acción de la droga; leí que esta puede inducir tendencias suicidas en el paciente [...], modorra [...], debilidad, fatiga, desorientación, ataxia, náuseas, embotamiento afectivo, reducción del estado de alerta, pérdida de apetito y de peso, somnolencia, sensación de ahogo, diplopía, visión borrosa o doble, agitación, alteraciones del sueño, mareos, vómitos, dolores de cabeza, perturbaciones sexuales, despersonalización, hiperacusia, entumecimiento y hormigueo de las extremidades, hipersensibilidad a la luz, al ruido y al contacto físico, alucinaciones o convulsiones epilépticas, problemas respiratorios, gastrointestinales y musculares, aumento de la hostilidad e irritabilidad, amnesia anterógrada, alteración de la percepción de la realidad y confusión mental, dificultades de pronunciación, anormalidades en las funciones del hígado y del riñón y síndrome de abstinencia tras interrupción brusca de la medicación. (26 y 27)

Sin embargo, ¿ahora qué? ¿Qué está haciendo el narrador al suplantar el lenguaje literario por estos lenguajes que hemos llamado listado, procedimental, del inventario, del expediente y prescriptivo (como algunos ejemplos de estas modalidades de la distancia).

Si recordamos a Dubrovsky, para él, la autoficción es un tipo de obra en el que se prescinde de un discurso lógico-cronológico en favor de una divagación poética y de un verbo errático en el que las palabras tienen preeminencia sobre las cosas y se toman por las cosas. De alguna manera, se constata que eso es lo que acontece en el modo de decir de este narrador. Agrega Dubrovsky: "Oscilación entre autobiografía y novela, entre texto y vida; una escritura inventada por la neurosis con una diferencia: si la neurosis hace entrar al sujeto en análisis, poniéndolo en la posición del analizado, cuando se vuelve narrador toma el lugar del analista" (Dubrovsky 1971:234).

De alguna manera, este narrador, primero está neutralizando el lenguaje, lo está llevando a su expresión básica, lo vacía, de cierto modo, del componente retórico (que le aportaría su literariedad). La consecuencia más directa de lo anterior es la pérdida de mundo. El

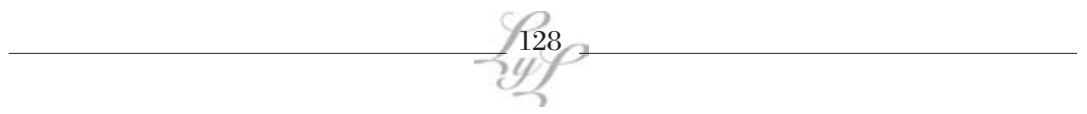


mundo está fuera: al administrarlo en listas y enumeraciones innumerables, el mundo no puede tocar ni ser tocado por el sujeto. Sin embargo, la consecuencia final de estas operaciones, se vincula con lo que describe Alberto Moreiras como una escritura postsimbólica: "lo que es reconocible como una vuelta de tuerca o torsión catastrófica de elementos alegóricos, que llevan la alegoría hacia el descubrimiento de las posibilidades epistémicas de una cierta alternativa postsimbólica" (Moreiras 1999: 75). Según Moreiras, estas operaciones se relacionan en su raíz misma con la escritura de duelo. En el caso de El espíritu..., el lenguaje de las listas, de los inventarios, empieza a contaminar lo que convencionalmente es considerado el lenguaje literario haciéndolo llevar al fracaso; la lengua común se encripta en virtud de una narrativa que se nutre, que encontrará en tal pérdida la fuerza suficiente para instalarse no en una nueva afirmación triunfante del símbolo, sino en "la entrada en una nueva posibilidad de escritura: escritura postsimbólica, escritura de duelo, traducción de epitafios" (Moreiras 1999). Esta opción del narrador de presentar la realidad (la suya, la de su familia, la de su país) en gran parte de la novela, haciendo uso de estas modalidades del lenguaje (y que él justifica con su "mala memoria") puede entenderse también como un acto de resistencia a toda formación totalizante. La renuncia a toda utopía y a toda metafísica. Desde esta perspectiva, el mundo aparece como objeto perdido. Objeto perdido que puede conmemorarse y en esa conmemoración se articula la resistencia y la instancia crítica del narrador, de acceso a un conocimiento de la existencia siempre incompleto, siempre singular y, paradójicamente, siempre irrepresentable en su totalidad.

La novela que nos ocupa, al mismo tiempo, se hermana a varias publicadas por escritores latinoamericanos nacidos después de 1970, en las cuales se presta (siguiendo ya una tradición latinoamericana asentada) una especial atención al hecho de la escritura, al gesto mismo de la escritura. Según Daniel Noemí al referirse a estas producciones: "La alegoría que sigue presente en estas narrativas es la de la escritura misma; toda escritura, nos dicen estas novelas y cuentos, es un escribir sobre el acto, palimpséstico por naturaleza, de escribir. La escritura es el grito desesperado, la resistencia, ante la crisis y la catástrofe". (Noemí en Montoya y Esteban eds. 2008:96). Esta alegoría de la escritura, en palabras de Noemí, es una presencia constante en la novela de Pron. Lo explicado anteriormente acerca de las diferentes modalidades que adopta el lenguaje (interviniendo el lenguaje literario) es una reflexión sobre el acto de escribir. Una constante metaficción. Se trata de un 
Migración, retorno y lenguaje en la narrativa latinoamericana de hoy: El espíritu de mis padres sigue subiendo en la lluvia de Patricio Pron / Pamela Tala

escritor en búsqueda de su expresión. Y en esa búsqueda, se posiciona ética y estéticamente:

Yo había querido ser como ellos y, de esa determinación, y de la voluntad que conllevaba, habían quedado como único testimonio aquel viaje a Alemania, que era el país donde los escritores que más me interesaban habían vivido y habían muerto y, sobre todo, habían escrito, y un puñado de libros que pertenecían ya a una literatura de la que yo había querido escapar sin lograrlo; una literatura que parecía ser la pesadilla de un escritor moribundo, o, mejor aún, de un escritor argentino y moribundo y sin ningún talento; digamos, para entendernos, un escritor que no fuera el autor de El Aleph, alrededor del cual todos giramos inevitablemente, sino más bien el de Sobre héroes y tumbas, alguien que toda su vida se creyó talentoso e importante y moralmente inobjetable y en el último instante de su vida descubre que careció de todo talento y se comportó ridículamente y recuerda que almorzó con dictadores y entonces se siente avergonzado y desea que la literatura de su país esté a la altura de su triste obra para que esta tenga incluso uno o dos epígonos y no haya sido escrita en vano. (15-16)

El texto escrito se desdobla constantemente en metatexto, con frecuentes referencias a la escritura (o falta de) que está teniendo lugar ante nuestros ojos.

Por otro lado (y también hermanándose de esta manera con un grupo de novelas latinoamericanas escritas a lo largo de los últimos años), el texto de Patricio Pron deviene además una investigación acerca del género narrativo, una investigación acerca de la novela y de la ficción y/o también de la autoficción, como se ha venido señalando. Esto lo hemos visto también en novelas como Missing. Una investigación (2009), del escritor chileno Alberto Fuguet o El síndrome de Ulises (2005) del colombiano Santiago Gamboa o en varios relatos del escritor peruano Santiago Rocangliolo (en los cuales incluso usa su propio nombre como nombre del protagonista); solo por nombrar algunos. Ha señalado Manuel Alberca:

Las autoficciones dan cuenta de la ruptura del contrato mimético en el terreno más comprometido, el de la supuesta transparencia referencial y en el de la evidencia autobiográfica, pues, al irrumpir «lo real» en el terreno de la invención (y viceversa) y el autorsujeto de la escritura en el campo de la literalidad, los esquemas receptivos y contractuales de la lectura novelesca o autobiográfica

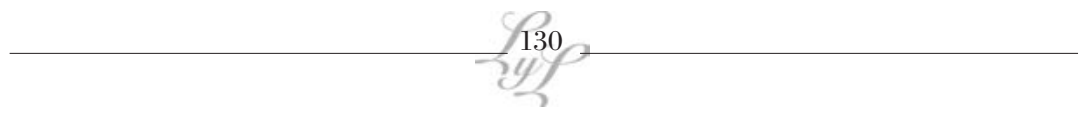


resultan subvertidos. En consecuencia, la inestabilidad referencial y enunciativa de la autoficción provoca una lectura oscilante entre el polo ficticio, que se reclama sobre todo de la inventio, y el autobiográfico, que no se satisface con la consideración meramente textual y sin referente externo. En realidad, la autoficción propone una gradación entre posiciones extremas, entre una lectura literal, basada en el principio de la verosimilitud, y otra referencial de acuerdo con las claves de la veracidad y la correspondencia extratextual". (Alberca 2009: 121)

En el caso de esta novela de Pron, todos los hechos y los datos básicos que estructuran la narración son biográficos: Patricio Pron deja Argentina a los 18 años, emigra a Alemania, donde se encuentra, 12 años después, cuando recibe la información de la inesperada y urgente enfermedad de su padre. Entonces decide regresar y descubre la investigación que su padre estaba realizando antes de caer enfermo. Todo al igual que el narrador. El mismo escritor lo afirma al final de la novela: "Aunque los hechos narrados en este libro son principalmente verdaderos, algunos son producto de las necesidades del relato de ficción, cuyas reglas son diferentes de las de géneros como el testimonio y la autobiografía; en este sentido, me gustaría mencionar aquí lo que dijera en cierta ocasión el escritor español Antonio Muñoz Molina, a modo de recordatorio y de advertencia: 'Una gota de ficción tiñe todo de ficción"' (Pron Epílogo: 198). Sin embargo, la novela de Pron, aporta un elemento más, muy novedoso, a este juego de desestabilizar el género, de desestabilizar la ficción: también en el Epílogo anuncia que su padre (el padre del escritor) quiso hacer ciertas observaciones al texto y a la historia ahí contada y esas observaciones pueden leerse en una página web creada especialmente para eso (lo que para un lector suspicaz podría significar una suerte de prolongación de la novela y de los juegos de espejos constantes en ella, pero que, en definitiva, son las palabras del padre de Patricio Pron):

Al leer el manuscrito de este libro, mi padre creyó importante [...] hacer algunas observaciones con la finalidad de dar su visión de los eventos narrados y reparar ciertos errores; el texto que reúne esas observaciones, y que resulta el primer testimonio de la clase de reacciones que este libro pretende provocar en primer lugar, se encuentra disponible bajo el vínculo http://patriciopron.blogspot. com/p/el-espiritu-de-mis-padres-sigue.html con el título de 'The Record Straight'. (198) 
Migración, retorno y lenguaje en la narrativa latinoamericana de hoy: El espíritu de mis padres sigue subiendo en la lluvia de Patricio Pron / Pamela Tala

\section{Conclusión}

La maquinaria narrativa de El espiritu de mis padres sigue subiendo en la lluvia se articula en gran medida como un juego de espejos. Espejos en los que se refleja la historia personal, la historia familiar, la historia nacional. Una mise en abyme tras otra, en esta constante búsqueda, no de la verdad, de una verdad, sino de una forma de expresión, de formas de expresión. Los ejemplos son múltiples: cuando el narrador describe (o transcribe) los efectos que determinada medicina produce, habla de despersonalización y lo que él está haciendo al transcribir es despersonalizar el lenguaje, intentar poner su intimidad en suspenso. La novela completa funciona como una máquina de espejos: el narrador deviene investigador de la investigación de su padre y a través de esta investigación se encuentra no solo con el rostro del padre, sino con el suyo propio: "Ahora pienso también (...) había una simetría y era una de acuerdo a la cual yo estaba buscando a mi padre y mi padre estaba testimoniando la búsqueda de otra persona, de una persona a la que él tal vez había conocido y que había desaparecido. También está el misterio de quién testimoniaba y de quién se había interesado por su búsqueda, pero ese misterio es casi irresoluble para mí". (60-61). De esta manera, el retorno -doloroso, incomprensible- ha tenido así, aparentemente, algún sentido. La exposición -casi involuntaria- no ha sido en vano. Porque el viaje del narrador es uno que también va desde la anomia y la indiferencia hacia la solidaridad (para la cual no es necesaria la completa comprensión) y la compasión. En una de las escenas finales de la novela (y una de las más emotivas) el narrador describe un momento a solas con su padre y la necesidad, llena de angustia y pena, que siente de decirle que sabe de su búsqueda, de sus "hermanos desaparecidos" y de cómo esa búsqueda (la de su padre) había sacado a la luz su propio recuerdo. Dice el narrador "Aguanta, tú y yo tenemos que hablar pero tú ahora no puedes y yo no puedo" y que luego siguió llorando en el pasillo del hospital.

La novela de Patricio Pron insiste en formular algunas interrogantes contemporáneas fundamentales: ¿cómo decimos hoy la historia, quiénes son los autorizados para decirla?, ¿cuáles son los límites del lenguaje ante el horror, ante la ausencia?, ¿es a la vez el lenguaje el que nos revincula con la comunidad? Se interroga (y desafía a la crítica literaria a hacerlo también) acerca del sentido que hoy adoptan conceptos como cosmopolitismo, hospitalidad, nación y globalidad, entre otros; al mismo tiempo que interroga a la propia lengua literaria y al género narrativo en esta búsqueda por expresar esta situación, de algún modo, inédita. Temas migratorios y lenguas migratorias. Del mismo modo (y pese a lo

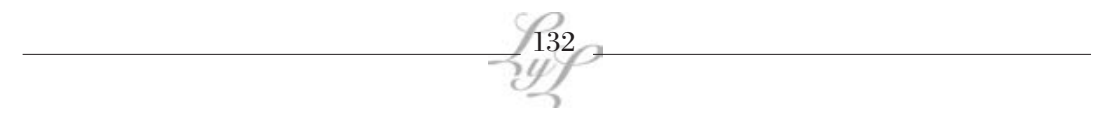


que se anuncia tantas veces por la crítica) queda a la vista que el tema de lo nacional, de la patria, está lejos de ser descartado por estos autores. Puede tomar la forma de un lamento nostálgico o rabioso, un llanto, un reclamo; pero presente.

Haciendo uso de una prosa sobria, contenida, el trabajo de Patricio Pron en esta novela, lejos de la trivialidad de la que se acusa a veces a los escritores de su edad, demuestra que -sin juegos de artificios- con renovadores registros, la pregunta sobre las heridas colectivas y la pregunta sobre la ética y la memoria se puede y se quiere seguir haciendo.

\section{Bibliografía}

Alberca, Manuel (2007). El pacto ambiguo. De la novela autobiográfica a la autoficción. Madrid: Biblioteca Nueva.

Coromines, Joan [1961] (2008). Breve diccionario etimológico de la lengua castellana. Prólogo de José Antonio Pascual. Madrid: Gredos.

Doubrovsky, Serge (1988). "Autobiographie/vérité/psychanalyse". Autobiographiques: de Corneille a Sartre. Paris: Presses Universitaires de France.

Lejeune, Philippe [1975] (1994). El pacto autobiográfico y otros estudios. Madrid: Endymion.

Ludmer, Josefina (2010). Aquí, América Latina. Una especulación. Buenos Aires: Eterna Cadencia editora.

Moreiras, Alberto (1999). Tercer espacio: literatura y duelo en América latina. Santiago: LOM Ediciones.

Molloy, Silvia, La Nación, 18 noviembre 2011, Buenos Aires.

y Mariano Siskind (eds.) (2005). Poéticas de la distancia. Adentro y afuera de la literatura argentina. Buenos Aires: Norma.

Montoya, Jesús y Esteban Ángel (eds) (2008). Entre lo local y lo global. La narrativa hispanoamericana en el cambio de siglo (19902006). Madrid: Iberoamericana Vervuert.

Pron, Patricio (2011). El espiritu de mis padres sigue subiendo en la lluvia. Barcelona: Random House Mondadori.

Rama, Ángel (1985). Rubén Darío y el modernismo. Caracas y Barcelona: Alfadil.

Rojo, Grínor (2009). Borgeana. Santiago: LOM Ediciones. 